\title{
Preparation of Modified Red Mud-Supported Fe Catalysts for Hydrogen Production by Catalytic Methane Decomposition
}

\author{
Quanrun Liu, ${ }^{1,2}$ Haipeng Li, ${ }^{1,2}$ Xiaoke Fang, ${ }^{1,2}$ Jingjie Zhang, ${ }^{1,2}$ Chuanxiang Zhang, \\ Mingjie Ma, ${ }^{1,2}$ Fenghai Li, ${ }^{1,3}$ and Guangxu Huang ${ }^{1,2}$ \\ ${ }^{1}$ School of Chemistry and Chemical Engineering, Henan Polytechnic University, Jiaozuo 454000, China \\ ${ }^{2}$ Collaborative Innovation Center of Coal Work Safety, Jiaozuo, Henan 454000, China \\ ${ }^{3}$ Department of Chemistry and Engineering, Heze University, Heze 274000, China \\ Correspondence should be addressed to Guangxu Huang; hgxu@hpu.edu.cn
}

Received 29 June 2017; Accepted 11 October 2017; Published 27 November 2017

Academic Editor: Andrew R. Barron

Copyright (C) 2017 Quanrun Liu et al. This is an open access article distributed under the Creative Commons Attribution License, which permits unrestricted use, distribution, and reproduction in any medium, provided the original work is properly cited.

\begin{abstract}
A modified red mud- (MRM-) supported Fe catalyst $(x \mathrm{Fe} / \mathrm{MRM})$ was prepared using the homogeneous precipitation method and applied to methane decomposition to produce hydrogen. The TEM and SEM-EDX results suggested that the particle sizes of the $x \mathrm{Fe} / \mathrm{MRM}$ catalysts were much smaller than that of raw red mud (RM), and the active metal Fe was evenly distributed over the catalyst structure. Moreover, BET results indicated that the surface areas and pore volumes of the catalysts were significantly improved, and the pore sizes of $x \mathrm{Fe} / \mathrm{MRM}$ were distributed from 5 to $12 \mathrm{~nm}$, which is typical for a mesoporous material. The activities of those catalysts for the catalytic decomposition of methane were studied at atmospheric pressure at a moderate temperature of $650^{\circ} \mathrm{C}$; the results showed that the $x \mathrm{Fe} / \mathrm{MRM}$ catalysts were more active than RM and MRM. The methane conversion curves of $x \mathrm{Fe} / \mathrm{MRM}$ catalysts exhibited similar variation tendencies (three-step) during the reaction despite different Fe contents, and the loading amount of Fe clearly affected the activity of the catalysts.
\end{abstract}

\section{Introduction}

In the last decade, hydrogen has become an attractive alternative energy because it is a powerful source of clean energy [1] that can be used to directly feed either combustion engines or different types of fuel cells and could avoid emission of greenhouse gases [2]. Compared with conventional hydrogen production from steam methane reformation [3-5], dry reforming [6,7], and partial oxidation of methane [8-11], pure hydrogen can be produced from catalytic methane decomposition (CMD) without by-products, such as $\mathrm{CO}$ and $\mathrm{CO}_{2}$. Therefore, $\mathrm{CMD}$ has become one of the most promising methods to prepare hydrogen and has received considerable attention.

Methane decomposition typically occurs at temperatures greater than $1000^{\circ} \mathrm{C}$, and in order to decrease the reaction temperature, the use of catalysts is required. Many works have been reported on CMD using metal catalysts, such as Fe [12-15], Co [16, 17], Ni [18-21], carbon materials [22-27], and their composite catalysts [28-30]. During methane decomposition, the carbon deposits were produced at the same time. Over the years, researchers have studied the structural and morphological characteristics of such carbon with the primary aim of determining the mechanism of its formation [14, 31-33].

Red mud (RM), a harmful by-product, is generated in the aluminium processing industry, and the main elements of $\mathrm{RM}, \mathrm{Fe}, \mathrm{Al}, \mathrm{Si}$, and $\mathrm{Ti}$ and smaller amounts of $\mathrm{Ca}$ and $\mathrm{Na}$ are potential alternative catalysts that are available on the commercial scale. Even after minor treatments, RM is still cheaper than both noble metals and metal oxides. Therefore, the catalytic application of red mud has wide prospects. In recent years, red mud has been investigated for various applications, such as an adsorbent for water and gas treatment and a catalyst for specific reactions, including hydrogenation [34], hydrodechlorination [35], exhaust gas clean-up [36], catalytic ammonia decomposition [37], and catalytic combustion of methane [38]. Balakrishnan et al. [39] have directly utilized 
three red mud samples for hydrogen production by CMD. The highest methane conversion obtained in their study was $19.8 \%$ with a corresponding methane conversion rate of 18.0 $\times 10^{-6} \mathrm{~mol} \mathrm{CH}_{4} / \mathrm{g}_{\text {cat }} / \mathrm{s}$, which is associated with a sample containing the highest proportion of iron, and two other samples exhibited poorer activity than this sample did. Fang et al. [40] found that a type of nanomesoporous modified red mud exhibited good activity and stability for decomposition of methane into hydrogen. Therefore, we speculate that the content of active metal may significantly impact the activity of RM for CMD.

The purpose of this study was to use red mud to prepare a type of catalyst by adding Fe using the homogeneous precipitation method in order to increase the active metal content and change the textural properties of the catalysts, leading to improving activity and/or stability of the catalysts applied to CMD.

\section{Experimental}

2.1. Preparation of $x \mathrm{Fe} / \mathrm{MRM}$ Catalyst. The original red mud (RM) sample was supported by Henan Zhongmei Aluminum Corporation, China. RM was dried (major compositions of dry $\mathrm{RM}$ (wt.\%): $\mathrm{Fe}_{2} \mathrm{O}_{3}, 16.10 \% ; \mathrm{Al}_{2} \mathrm{O}_{3}, 25.95 \% ; \mathrm{SiO}_{2}, 18.35 \%$; $\mathrm{CaO}, 18.19 \% ; \mathrm{TiO}_{2}, 4.77 \% ; \mathrm{Na}_{2} \mathrm{O}, 4.33 \%$; and $\mathrm{MgO}, 2.49 \%$, as detected by XRF and shown in Table 1), ground, and sieved to a size of $<75 \mu \mathrm{m}$.

The $x \mathrm{Fe} / \mathrm{MRM}$ catalysts were prepared using a typical homogeneous precipitation process. A total of $10 \mathrm{~g}$ of dried red mud sample was added to $100 \mathrm{ml}$ of deionized water, the sample was ultrasonicated for $3 \mathrm{~min}$, and then $400 \mathrm{ml}$ of $1.25 \mathrm{M} \mathrm{HCl}$ solution was added. The resulting solution was heated at $60^{\circ} \mathrm{C}$ in a water bath and magnetically stirred for $2 \mathrm{~h}$. An amount of $\mathrm{Fe}\left(\mathrm{NO}_{3}\right)_{3} \cdot 9 \mathrm{H}_{2} \mathrm{O}$ (calculated according to the stoichiometric ratio) was dissolved in $50 \mathrm{ml}$ of anhydrous ethanol and added to the above solution. Then, the solution was precipitated by slowly adding aqueous ammonia while vigorously stirring until the $\mathrm{pH}$ reached 8 . The obtained precipitate was filtered, washed with deionized water and anhydrous ethanol several times, and then dried at $105^{\circ} \mathrm{C}$ and calcined in air at $600^{\circ} \mathrm{C}$ for $2 \mathrm{~h}$ (the samples that have not been reduced were denoted as catalyst precursors). Finally, the catalyst precursor was reduced with $\mathrm{H}_{2}$ in a vertical stainless steel fixed-bed reactor at $600^{\circ} \mathrm{C}$ for $4 \mathrm{~h}$ and then ground and sieved to a size of $<75 \mu \mathrm{m}$. The obtained catalysts were denoted as $x \mathrm{Fe} / \mathrm{MRM}$ (the catalyst prepared using the same procedure without the addition of Fe was defined as MRM), where $x$ is the quality percentage of Fe-based dry RM, which can be expressed as follows:

$$
x=\frac{W_{\mathrm{Fe}}}{W_{\mathrm{RM}_{\mathrm{dry}}}} \times 100 \%,
$$

where $W_{\mathrm{Fe}}$ is the weight of metal Fe (calculated according to the stoichiometric ratio of $\left.\mathrm{Fe}\left(\mathrm{NO}_{3}\right)_{2} \cdot 9 \mathrm{H}_{2} \mathrm{O}\right)$ and $W_{\mathrm{RM}_{\text {dry }}}$ is the weight of dried RM.

2.2. Methane Decomposition Reaction. Catalytic methane decomposition (CMD) tests were conducted in a vertical stainless steel fixed-bed reactor $(8 \mathrm{~mm}$ i.d.) at atmospheric pressure. A total of $0.50 \mathrm{~g}$ of catalyst was placed into the center of the reactor and heated to $650^{\circ} \mathrm{C}$ under $\mathrm{N}_{2}$ with a flow rate of $30 \mathrm{ml} / \mathrm{min}$. Next, pure $\mathrm{CH}_{4}(99.99$ vol.\%) with a total volumetric hourly space velocity (VHSV) of $4.8 \mathrm{~L} /\left(\mathrm{h} \cdot \mathrm{g}_{\text {cat }}\right.$ ) was introduced into the reactor instead of $\mathrm{N}_{2}$. The gas products were analyzed online by a gas analyzer that adopted the advanced nondispersive infra-red (NDIR) technology and thermal conductivity detector (TCD) technology to measure the volume percentages of $\mathrm{CO}, \mathrm{CO}_{2}, \mathrm{O}_{2}, \mathrm{CH}_{4}, \mathrm{H}_{2}$, and $\mathrm{C}_{n} \mathrm{H}_{m}$. The conversion of methane was calculated from the following expression [33]:

$$
x_{\mathrm{CH}_{4}}=\frac{\% \mathrm{H}_{2}}{200-\% \mathrm{H}_{2}} \times 100,
$$

where $x_{\mathrm{CH}_{4}}$ is the conversion of methane and $\% \mathrm{H}_{2}$ is the volume percentage of $\mathrm{H}_{2}$ production.

2.3. Characterization. X-ray diffraction (XRD) analysis was performed on a Bruker-AXS D8 Advance diffractometer with $\mathrm{CuKa}$ radiation at $40 \mathrm{kV}$ and $25 \mathrm{~mA}$ in a scanning range from $10-90^{\circ}(2 \theta)$ with a step size of $0.2^{\circ}$ and a counting rate of $2 \mathrm{~s}$ per step. $\mathrm{N}_{2}$ adsorption/desorption isotherms were obtained on a Quantachrome AsiQM0000-3 sorption analyzer. Before the measurements were recorded, each sample was outgassed at $180^{\circ} \mathrm{C}$ for $6 \mathrm{~h}$. Thermogravimetry-differential thermal gravity (TG-DTG) analysis was performed on a NETZSCH STA449C Simultaneous Thermal Analyzer in the temperature range from room temperature to $800^{\circ} \mathrm{C}$ under $\mathrm{N}_{2}$ of $20 \mathrm{ml} / \mathrm{min}$. Scanning electron microscopy (SEM) was conducted on an FEI Quanta FEG 250 to record the morphology of the samples before and after the CMD reactions, and energy-dispersive X-ray spectroscopy (EDX) was performed on a Bruker QUANTAX-200 XFlash to observe the Fe dispersity. Transmission electron microscopy (TEM) analysis was performed on a JEOL JEM-2100 microscope operated at $200 \mathrm{kV}$.

\section{Results and Discussion}

3.1. XRD and XRF Analyses of Catalysts. Table 1 shows the main chemical composition (detected by XRF) of $120^{\circ} \mathrm{C}$ dried $\mathrm{RM}$ (dry RM) and $600^{\circ} \mathrm{C}$ calcined catalyst precursors with different Fe contents (termed $x$ Fe/MRM-600). The contents of $\mathrm{CaO}$ and $\mathrm{Na}_{2} \mathrm{O}$ in those $x \mathrm{Fe} / \mathrm{MRM}-600$ catalyst precursors were much lower than those in dry RM, suggesting that most of $\mathrm{Ca}$ and $\mathrm{Na}$ were removed during catalyst preparation [41]. The content of $\mathrm{Fe}_{2} \mathrm{O}_{3}$ in those $x \mathrm{Fe} / \mathrm{MRM}-600$ catalyst precursors gradually increased with Fe loading, and the content of the other components, such as $\mathrm{Al}_{2} \mathrm{O}_{3}$ and $\mathrm{SiO}_{2}$, gradually decreased with increased Fe loading.

The XRD patterns of those $x \mathrm{Fe} / \mathrm{MRM}-600$ catalyst precursors with different $\mathrm{Fe}$ contents are shown in Figure 1. The characteristic peaks of $\mathrm{SiO}_{2}$ with $2 \theta$ of $26.188^{\circ}$ and $\gamma$ $\mathrm{Al}_{2} \mathrm{O}_{3}\left(19.493^{\circ}, 32.778^{\circ}\right.$, and $\left.34.742^{\circ}\right)$ were detected in the XRD patterns of the $600^{\circ} \mathrm{C}$ calcined MRM catalyst precursor (MRM-600), and these diffraction peaks became weaker and weaker with increased Fe loadings. The typical peaks attributed to $\mathrm{Fe}_{2} \mathrm{O}_{3}$ species $\left(24.138^{\circ}, 33.152^{\circ}, 35.611^{\circ}, 40.854^{\circ}\right.$, 
TABLE 1: The main components of dry RM and $600^{\circ} \mathrm{C}$ calcined $x \mathrm{Fe} / \mathrm{MRM}$ catalysts precursor.

\begin{tabular}{|c|c|c|c|c|c|c|c|}
\hline \multirow{2}{*}{ Samples } & \multicolumn{7}{|c|}{ Main components (\%) } \\
\hline & $\mathrm{Al}_{2} \mathrm{O}_{3}$ & $\mathrm{SiO}_{2}$ & $\mathrm{Fe}_{2} \mathrm{O}_{3}$ & $\mathrm{TiO}_{2}$ & $\mathrm{CaO}$ & $\mathrm{MgO}$ & $\mathrm{Na}_{2} \mathrm{O}$ \\
\hline Dry RM & 25.95 & 18.35 & 16.10 & 4.77 & 18.19 & 2.49 & 4.33 \\
\hline MRM-600 & 32.18 & 23.25 & 21.98 & 6.43 & 2.23 & 2.87 & 0.57 \\
\hline 10Fe/MRM-600 & 28.73 & 20.59 & 34.62 & 5.91 & 2.65 & 0.55 & 0.49 \\
\hline 20Fe/MRM-600 & 23.84 & 17.27 & 41.36 & 5.11 & 4.07 & 0.50 & 0.71 \\
\hline 30Fe/MRM-600 & 20.51 & 14.60 & 49.70 & 4.50 & 2.75 & 0.38 & 0.47 \\
\hline 40Fe/MRM-600 & 17.55 & 11.91 & 56.16 & 3.93 & 2.27 & 0.25 & 0.43 \\
\hline
\end{tabular}

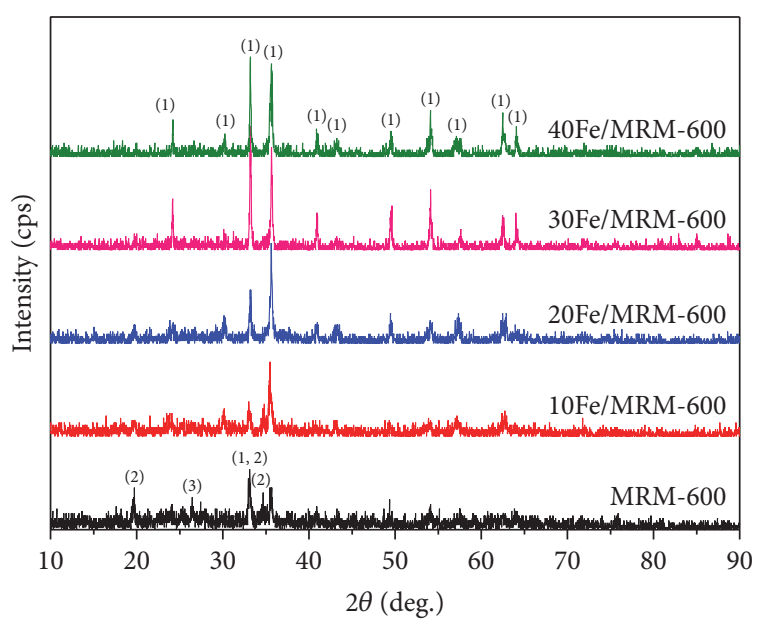

(1) $\mathrm{Fe}_{2} \mathrm{O}_{3}$

(2) $\mathrm{Al}_{2} \mathrm{O}_{3}$

(3) $\mathrm{SiO}_{2}$

FIGURE 1: The XRD spectrum of the $600^{\circ} \mathrm{C}$ calcined catalyst precursors with different Fe content.

$43.51^{\circ}, 49.479^{\circ}, 54.08^{\circ}, 57.428^{\circ}, 62.449^{\circ}$, and $63.989^{\circ}$ ) were observed, and the intensities gradually increased with the Fe content in the patterns of those $x$ Fe/MRM- 600 catalyst precursors, which corresponds with the XRF analysis shown in Table 1.

Figure 2 shows the XRD patterns of five sample types that included $600^{\circ} \mathrm{C}$ calcined RM (denoted as RM-600), $600^{\circ} \mathrm{C}$ calcined catalyst precursors (MRM-600 and 20Fe/MRM600 ), and 20Fe/MRM catalyst before and after CMD. The purpose of Figure 2 was to study the compositions and phase changes of the catalysts during the entire experimental process, so we chose those five samples as the examples. From the pattern of RM-600, the characteristic peaks of the $\mathrm{NaAlSi}_{3} \mathrm{O}_{8}$ species $\left(13.957^{\circ}, 24.299^{\circ}\right.$, and $\left.27.681^{\circ}\right)$ and $\mathrm{CaCO}_{3}$ species $\left(29.400^{\circ}\right)$ were clearly observed; however, no peaks corresponding to these two species were found in the MRM600 and 20Fe/MRM-600 samples, which suggested that most of $\mathrm{Na}$ and $\mathrm{Ca}$ were almost completely removed. This observation was also fully confirmed by the XRF analysis shown in Table 1 . In the pattern of the 20Fe/MRM catalyst, almost no peaks ascribed to the $\mathrm{Fe}_{2} \mathrm{O}_{3}$ species $\left(24.138^{\circ}, 33.152^{\circ}, 35.611^{\circ}\right.$, $40.854^{\circ}, 43.51^{\circ}, 49.479^{\circ}, 54.08^{\circ}, 57.428^{\circ}, 62.449^{\circ}$, or $\left.63.989^{\circ}\right)$ were found, but the characteristic Fe peaks $\left(44.662^{\circ}, 65.006^{\circ}\right.$,

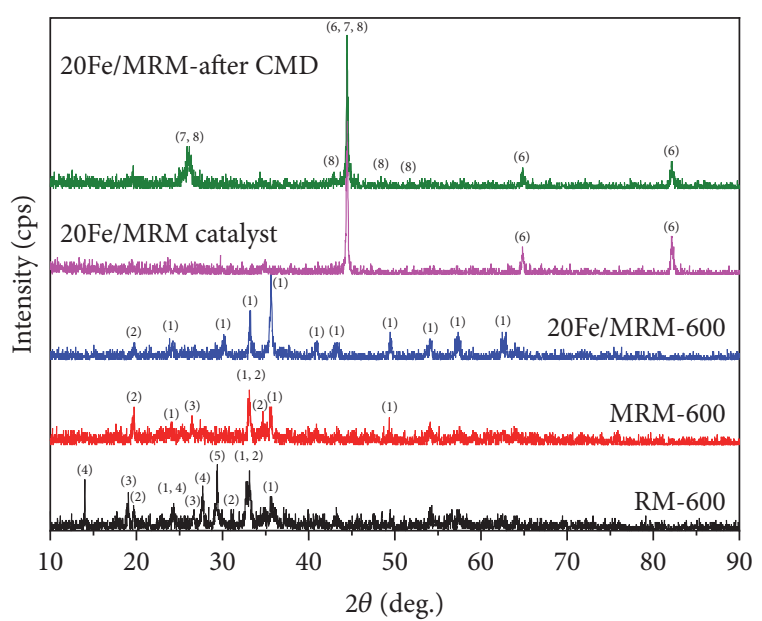
(1) $\mathrm{Fe}_{2} \mathrm{O}_{3}$
(4) $\mathrm{NaAlSi}_{3} \mathrm{O}_{8}$
(2) $\mathrm{Al}_{2} \mathrm{O}_{3}$
(5) $\mathrm{CaCO}_{3}$
(7) Graphitic C
(3) $\mathrm{SiO}_{2}$
(6) $\mathrm{Fe}$
(8) $\mathrm{Fe}_{3} \mathrm{C}$

FIGURE 2: The XRD spectrum of different samples.

and $82.311^{\circ}$ ) were detected because the $\mathrm{Fe}_{2} \mathrm{O}_{3}$ species was reduced by $\mathrm{H}_{2}$ at $600^{\circ} \mathrm{C}$. After $\mathrm{CMD}$, the peaks ascribed to the Fe species were also clearly seen in the pattern of 20Fe/MRM-after CMD, but the peak intensities with $2 \theta$ of $65.006^{\circ}$ and $82.311^{\circ}$ were weaker than the $20 \mathrm{Fe} / \mathrm{MRM}$ catalyst, which may be attributed to carbon deposits produced during CMD. Moreover, the peak intensities with $2 \theta$ of $44.662^{\circ}$ in the pattern of the 20Fe/MRM-after CMD were stronger than 20Fe/MRM catalyst. This interesting phenomenon may be ascribed to superimposition of the graphitic C [42] peak $(2 \theta$ of $\left.44.608^{\circ}\right)$ and the cementite $\mathrm{Fe}_{3} \mathrm{C}$ peak $\left(2 \theta\right.$ of $\left.44.575^{\circ}\right)$ with the Fe peak $\left(2 \theta\right.$ of $\left.44.662^{\circ}\right)$. The diffraction peak of graphitic C $\left(2 \theta\right.$ of $\left.26.522^{\circ}\right)$ was superimposed with the cementite $\mathrm{Fe}_{3} \mathrm{C}$ peak $\left(2 \theta\right.$ of $\left.26.426^{\circ}\right)$. In addition, the cementite $\mathrm{Fe}_{3} \mathrm{C}$ peak $\left(26.413^{\circ}, 44.575^{\circ}, 42.893^{\circ}, 44.575^{\circ}, 44.997^{\circ}, 48.600^{\circ}\right.$, and $51.843^{\circ}$ ) was observed from the pattern of the $20 \mathrm{Fe} / \mathrm{MRM}-$ after CMD; this species has also been discovered by Sushil et al. [42] and Torres et al. [17]. Next, the morphology and structure of the carbons were determined (see below).

3.2. TG-DTG Analysis. Figure 3 shows the thermogravimetry (TG) and derivative thermogravimetry (DTG) curves of the original RM and uncalcined 20Fe/MRM catalyst precursor (the obtained precipitate dried at $105^{\circ} \mathrm{C}$ ). The total weight 


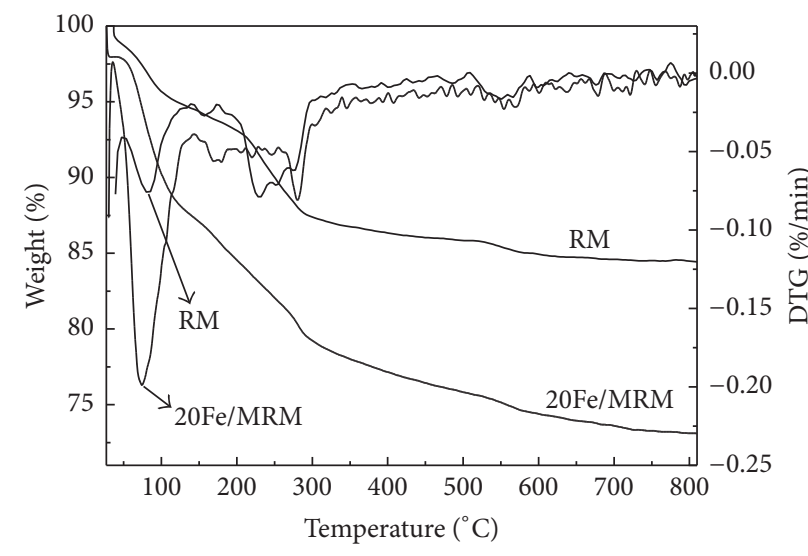

FIgURE 3: The TG-DTG analysis of original RM and uncalcined 20Fe/MRM catalyst precursor.

loss of RM was $15.53 \%$ from ambient temperature to $800^{\circ} \mathrm{C}$, and the TG curve showed three weight loss steps. The first weight loss $(5.01 \%)$ step occurred in the temperature range from 35 to $124^{\circ} \mathrm{C}$ due to evaporation of physically adsorbed water; the second weight loss (7.46\%) between 124 and $292^{\circ} \mathrm{C}$ was ascribed to the remaining crystal water, partial decomposition of hydroxides, such as gibbsite decomposed into boehmite [43], and transformation of goethite to hematite [44]. The final step occurred in the temperature range from 292 to $636^{\circ} \mathrm{C}$, in which the weight loss was approximately $2.79 \%$ of the total weight, which may be attributed to decomposition of the remaining hydroxides and release of $\mathrm{CO}_{2}$ during decomposition of carbonate [45].

The TG curves of the uncalcined 20Fe/MRM catalyst precursor showed three weight loss steps that were similar to those of RM, revealing that the continuous weight loss was approximately $26.89 \%$ of the total weight from room temperature to $800^{\circ} \mathrm{C}$. The first weight loss of $12.51 \%$ from 25 to $139^{\circ} \mathrm{C}$ was ascribed to the physically adsorbed water; the second weight loss of $8.02 \%$ from 139 to $294^{\circ} \mathrm{C}$ may be due to gibbsite and Fe hydroxide (formed in the homogeneous precipitation process during catalyst preparation) decomposing into $\gamma-\mathrm{Al}_{2} \mathrm{O}_{3}$ [46] and hematite, respectively; the third weight loss of $6.36 \%$ in the temperature range from 294 to $800^{\circ} \mathrm{C}$ was attributed to decomposition of the remaining hydroxides. The uncalcined $20 \mathrm{Fe} / \mathrm{MRM}$ catalyst precursor exhibited a greater total weight loss than RM, which indicated a greater hydroxide content in the uncalcined 20Fe/MRM catalyst precursor than in RM due to the added Fe contents that directly increased the iron hydroxide formed during the precipitation process. The purpose of the calcining process in catalyst pretreatment is to transform the hydroxides into metal oxides and improve the pore structure as much as possible; however, high temperature can cause sintering of the pore structure and lead to decreased surface areas [47]. Therefore, based on the above analysis, the calcining temperature chosen in this study was $600^{\circ} \mathrm{C}$.

3.3. Surface Areas and Textural Properties of the Catalysts. To investigate the surface area and textural property changes of
TABLE 2: The textural properties of samples.

\begin{tabular}{lccc}
\hline Samples & $\begin{array}{c}\text { Surface area } \\
\left(\mathrm{m}^{2} / \mathrm{g}\right)\end{array}$ & $V_{\text {tot }}\left(\mathrm{cm}^{3} / \mathrm{g}\right)$ & $\begin{array}{c}\mathrm{D}_{\text {DFT-ads }} \mathrm{b} \\
(\mathrm{nm})\end{array}$ \\
\hline Dry RM & 8.05 & 0.08 & 14.64 \\
MRM-600 & 190.61 & 0.39 & 4.80 \\
20Fe/MRM-600 & 148.91 & 0.29 & 4.97 \\
MRM catalyst & 139.89 & 0.31 & 4.54 \\
20Fe/MRM catalyst & 81.36 & 0.26 & 6.23 \\
20Fe/MRM-after CMD & 62.21 & 0.20 & 11.17 \\
\hline
\end{tabular}

${ }^{a}$ Multipoint BET surface area. ${ }^{b}$ Maximum of DFT pore diameter as determined from the adsorption branch.

the catalysts during the entire experimental process, nitrogen adsorption/desorption was conducted for each sample, which included dry $\mathrm{RM}, 600^{\circ} \mathrm{C}$ calcined catalysts precursors (MRM-600 and 20Fe/MRM-600), catalysts (MRM and 20Fe/MRM), and 20Fe/MRM-after CMD. As presented in Table 2, the surface areas and total pore volumes of the $600^{\circ} \mathrm{C}$ calcined catalyst precursors (MRM-600 and 20Fe/MRM600) and catalysts (MRM and 20Fe/MRM) were much higher than those of dry RM. For example, the surface area and total pore volume of the MRM catalyst dramatically increased from $8.05 \mathrm{~m}^{2} / \mathrm{g}$ and $0.08 \mathrm{~cm}^{3} / \mathrm{g}$ to $139.89 \mathrm{~m}^{2} / \mathrm{g}$ and $0.31 \mathrm{~cm}^{3} / \mathrm{g}$, respectively. However, the surface area and total pore volume of MRM-600 substantially decreased after it was reduced by $\mathrm{H}_{2}$, and the same behaviour was observed for 20Fe/MRM600. This observation may be attributed to the $\mathrm{Fe}_{2} \mathrm{O}_{3}$ species transforming into iron metal in the catalyst reduction process, which was confirmed by the XRD analysis shown in Figure 2. An important observation was that the surface area and total pore volume of the catalyst decreased when metal Fe was introduced into the catalyst, as shown in Table 2, and the surface area decreased from 139.89 to $81.36 \mathrm{~m}^{2} / \mathrm{g}$ in the MRM catalyst when $20 \%$ (quality percentage) Fe was added. This phenomenon has also been reported by many researchers $[18,28]$. Another noticeable result was that the surface area and total pore volume of the $20 \mathrm{Fe} / \mathrm{MRM}$ catalyst decreased significantly after CMD, suggesting that the pore structure of the catalyst was somehow destroyed during CMD.

Figure 4 shows the $\mathrm{N}_{2}$ adsorption/desorption isotherms (a) and the corresponding pore size distribution curves (b) for the samples. The isotherm of dry RM was categorized as classical type I (according to IUPAC), and there was no apparent peak in the pore size distribution curve. The isotherms of $600^{\circ} \mathrm{C}$ calcined catalyst precursors (MRM-600 and 20Fe/MRM-600) and catalysts (MRM and 20Fe/MRM) were categorized as classical type IV. The hysteresis loops belonged to the $\mathrm{H}_{2}$ type with steep adsorption and desorption branches, suggesting that the catalysts possessed a typical mesoporous structure [47]. From the pore size distribution curves in Figure 4(a), we determined that the pore sizes of the 20Fe/MRM catalysts were distributed from 5 to $12 \mathrm{~nm}$. After $\mathrm{CMD}$, the pore sizes of 20Fe/MRM-after CMD were different from those of 20Fe/MRM catalyst and were distributed from 2 to $15 \mathrm{~nm}$. The pore volume of the $20 \mathrm{Fe} / \mathrm{MRM}$ catalyst ( 5 to $10 \mathrm{~nm}$ ) was much smaller than 20Fe/MRM-after CMD, and 


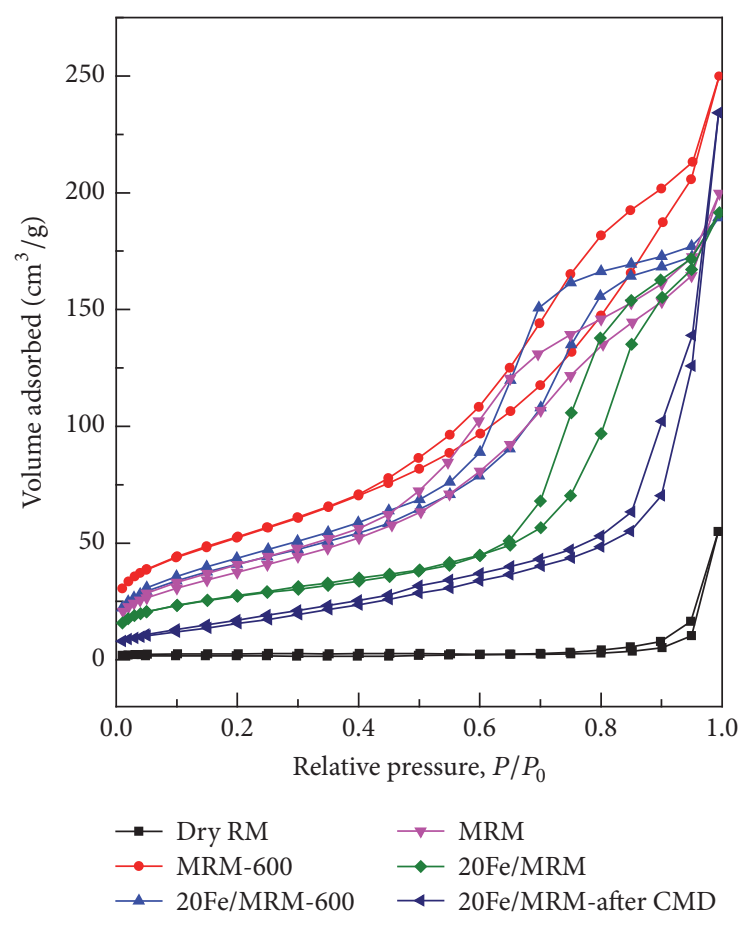

(a)

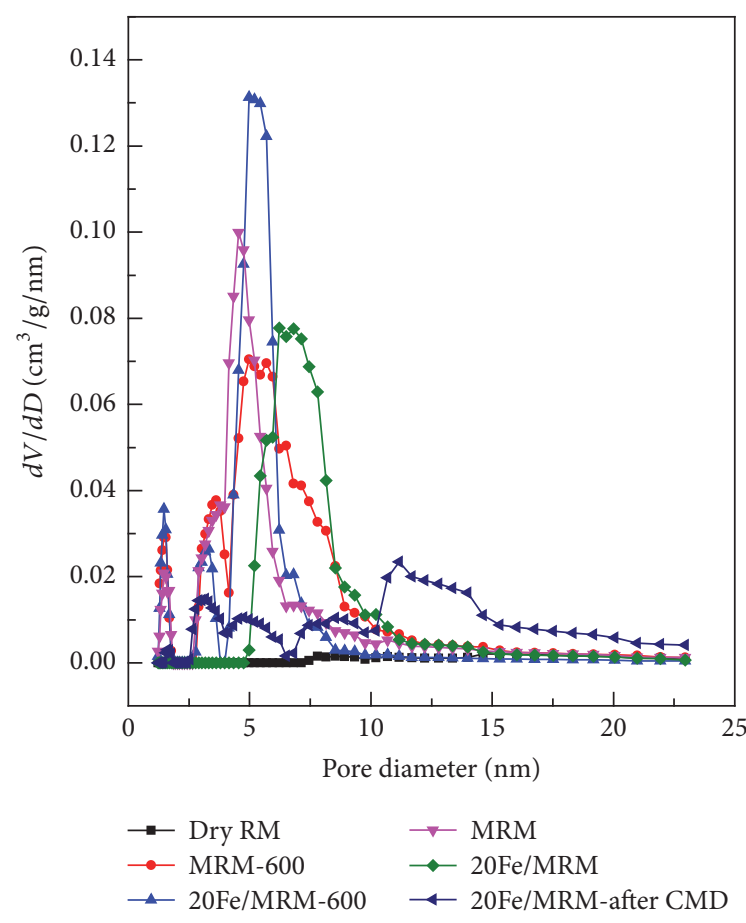

(b)

FIGURE 4: $\mathrm{N}_{2}$ adsorption/desorption isotherms (a) and the corresponding pore size distribution curves (b) of samples.

the pore volume of the latter from 10 to $15 \mathrm{~nm}$ was much larger than the former, which may be attributed to formation of carbon deposits during CMD, causing the original pore structure of the $20 \mathrm{Fe} / \mathrm{MRM}$ catalyst to be destroyed and a new pore structure to be formed. An interesting phenomenon shown in Figure 4(b) was that the pore size distribution range of $20 \mathrm{Fe} / \mathrm{MRM}-600(3-8 \mathrm{~nm})$ was narrower than that of MRM-600 (2-12 nm). The reason for this observation was not definite, so we investigated the morphologies of these two samples using TEM.

3.4. Morphologies of Catalysts. The TEM images of dry $\mathrm{RM}$ and $600^{\circ} \mathrm{C}$ calcined catalyst precursors (MRM-600 and 20Fe/MRM-600) are shown in Figure 5. From Figure 5(a), the dry RM particles with a variety of different sizes and forms were observed. After modified treatment, RM particles were decomposed into uniform, small MRM-600 particles (see Figure 5(b)), showing abundant wormhole-like pore structures. This observation corresponded with the BET analysis (see Figure 4 and Table 2). However, from Figures 5(b) and 5(c), the 20Fe/MRM-600 particles were interestingly much smaller than the MRM-600 particles; the particle morphology of the former showed much better uniformity than the latter. This attractive trait may be attributed to addition of the Ferric nitrate solution in the homogeneous precipitation process. The higher concentration of iron ions led to a slower precipitation rate because the concentration and rate of aqueous ammonia addition were constant in this study; therefore, the sizes of the precipitated particles generated in 20Fe/MRM-600 were smaller than MRM-600. This inference was also confirmed by observing the samples under higher magnification, which is shown in Figures 5(d) and 5(e). As mentioned above, the pore sizes of MRM- 600 and 20Fe/MRM-600 were distributed from 2 to $12 \mathrm{~nm}$ and from 3 to $8 \mathrm{~nm}$ (see Figure 4(b)), respectively. These results indicated better uniformity of the particles and a narrower pore size distribution range of the catalysts; that is, the shapes and sizes of the particles affected the pore size distributions.

An EDX analysis of the 20Fe/MRM catalyst was performed to determine whether the active metal Fe had been uniformly distributed over the catalyst structure. This is a crucial aspect because the distribution of active metal over the catalyst structure significantly impacts the activity of the catalysts in CMD [48]. Homocondensation needs to be avoided in order to achieve a structure with highly disperse cations and minimize the local intensity of active iron.

The SEM-EDX maps of fresh 20Fe/MRM are shown in Figure 6. From Figure 6(b), elemental Fe clearly exhibited a fine distribution, and the other elements, including silicon, aluminium, and titanium, all exhibited fine distributions also. For example, the element silicon was dispersed uniformly, as seen in Figure 6(c). The main forms of the elements aluminium and silicon in the fresh 20Fe/MRM catalyst were $\mathrm{Al}_{2} \mathrm{O}_{3}$ and $\mathrm{SiO}_{2}$ (see Figure 1), respectively, which have been used as carriers and textural promoters of the catalyst to enhance Fe dispersion as much as possible.

3.5. Catalytic Methane Decomposition. In the CMD reaction, $\mathrm{CH}_{4} \rightarrow \mathrm{C}(\mathrm{s})+2 \mathrm{H}_{2}(\mathrm{~g})$, the by-product of carbon deposits is always accompanied with hydrogen production. Consequently, the pressure drop across the reactor should increase and lead to a decreased methane flow rate and longer 


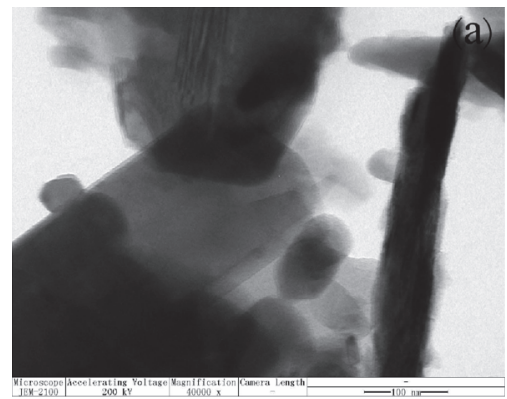

(a)

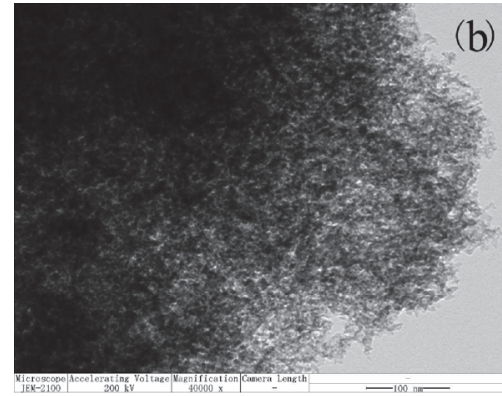

(b)

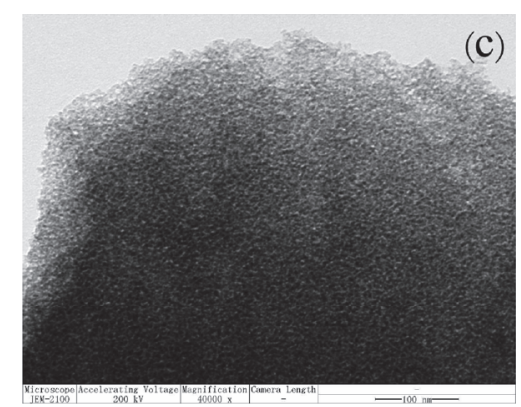

(c)

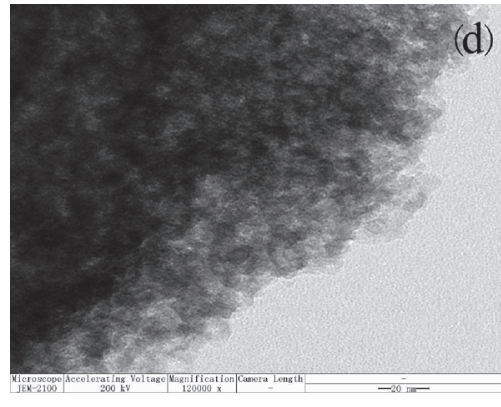

(d)

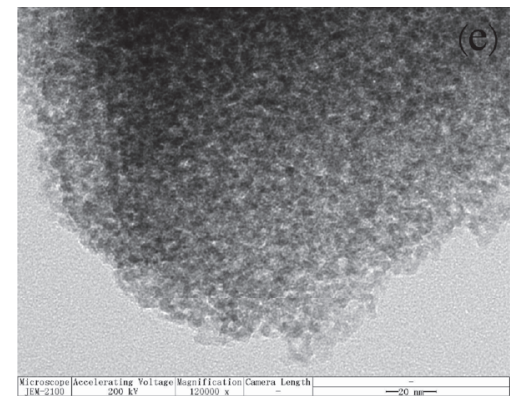

(e)

FIGURE 5: TEM images of samples: (a) original RM; ((b) and (d)) $600^{\circ} \mathrm{C}$ calcined MRM precursor; ((c) and (e)) $600^{\circ} \mathrm{C}$ calcined $20 \mathrm{Fe} / \mathrm{MRM}$ precursor.

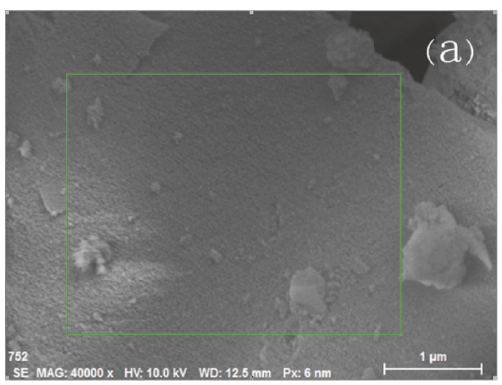

(a)

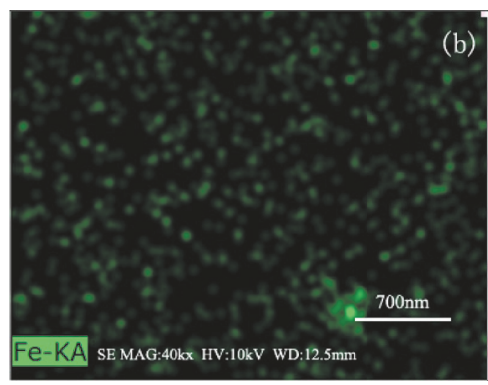

(b)

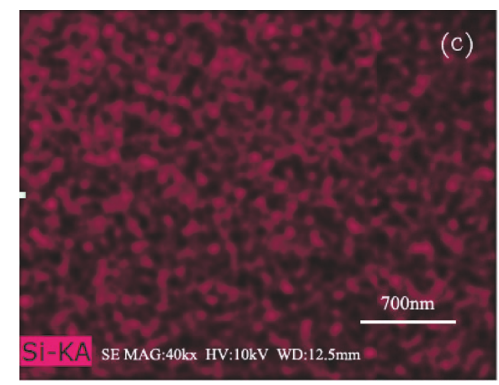

(c)

Figure 6: The EDX analysis for the 20Fe/MRM catalyst showing the SEM picture (a), the iron distribution (b), and the silicon distribution (c).

residence time [29]. Therefore, the CMD reaction in this study was stopped before the pressure and/or methane flow rate changed. We found that different samples have different timespans when the pressure increased and methane flow rate changed, which may be due to the different composition of the samples. Therefore, different samples have to be treated for different overall timespans in this study.

The catalytic activities and stabilities of different catalysts for $\mathrm{CMD}$ at $650^{\circ} \mathrm{C}$ were compared, and the results are shown in Figure 7. RM and MRM had much lower activity than the Fe-added catalysts (10Fe/MRM, 20Fe/MRM, 30Fe/MRM, and $40 \mathrm{Fe} / \mathrm{MRM}$ ), and the methane conversion obtained over RM and MRM was always less than 4\% during the reaction. This behaviour indicated that the original metal Fe species in MRM may not be able to provide enough active center for $\mathrm{CMD}$ in such a moderate condition. When metal $\mathrm{Fe}$ was loaded onto MRM, the catalytic activity significantly increased, proving that methane conversion strongly depends on the $\mathrm{Fe}$ content in the catalysts. For example, methane conversion for the 20Fe/MRM catalyst increased from 9.07 to $31.46 \%$ during the first 60 minutes, which was much higher than RM and MRM during the entire reaction time. However, the initial methane conversions ( 5 minutes after the reaction started) of the $x \mathrm{Fe} / \mathrm{MRM}$ catalysts were similarly less than $10 \%$ despite the different Fe contents. However, after a period of approximately 35 minutes, methane conversion obviously increased and the catalysts with different Fe contents exhibited different catalytic activities, indicating that Fe metal served as the predominant catalytic center and the loading amount significantly impacted the activity of the catalysts. As reported by Jin et al. [28], there may be an induced period required before Fe particles develop to their full capacities, 


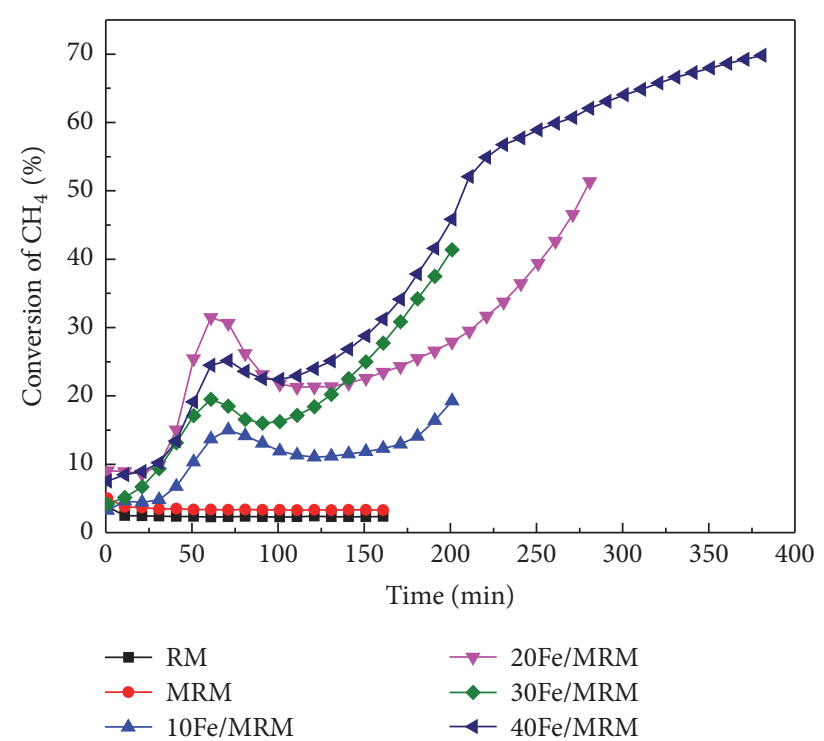

Figure 7: The activities of all the catalysts for CMD at $650^{\circ} \mathrm{C}$.

and this result was also found in Ni-doped carbon catalysts [29].

From Figure 7, the methane conversion curves for different Fe content catalysts (10Fe/MRM, 20Fe/MRM, 30Fe/ MRM, and 40Fe/MRM) show similar three-step (increasedecrease-increase) variations with the reaction time, and the variation tendency of methane conversion curves was different in contrast with conventional iron-based catalysts $[14,49]$. The first step was ascribed to the induction period that was mentioned above. In the second step, methane conversion showed a slow decrease with the reaction time, which may be due to inactive carbon deposits [22, 24] produced during CMD which covered the Fe active sites, although the catalysts were not completely deactivated. In the third step, methane conversion showed a quick increase with the reaction time and stably continued to increase, which indicated that some other factors besides Fe played a role in improving methane conversion during this time. For example, methane conversion of the fresh 20Fe/MRM catalyst was stable (approximately 9\%) for a short time (approximately 20 minutes) at the beginning of the reaction and then showed a quick increase as the reaction time was increased, and, after another 40 minutes, methane conversion increased to $31.46 \%$, suggesting that the Fe particles were developed to their full capacities. Methane conversion gradually decreased to $21.29 \%$ at 110 minutes; then the methane conversion curve rose quickly after 270 minutes of CMD, increasing to $46.57 \%$. This fully confirmed that the three-step variation in the methane conversion curve was mainly related to the catalytic behaviour of the catalysts [28].

In addition, the peak conversion of methane in this study was $69.8 \%$, obtained over the $40 \mathrm{Fe} / \mathrm{MRM}$ catalyst at $650^{\circ} \mathrm{C}$, and the corresponding methane conversion rate was 41.5 $\times 10^{-6} \mathrm{~mol} \mathrm{CH}_{4} / \mathrm{g}_{\mathrm{cat}} / \mathrm{s}$, which was much higher than that obtained by Balakrishnan et al. [39] at $800^{\circ} \mathrm{C}\left(18.0 \times 10^{-6} \mathrm{~mol}\right.$ $\left.\mathrm{CH}_{4} / \mathrm{g}_{\text {cat }} / \mathrm{s}\right)$.
Next, the morphologies and structures of carbon deposits were explored.

3.6. Formation of Carbon Deposits. As we know, carbon deposits play a significant role in the activity and stability of catalysts, and catalyst lifetimes greatly depend on the morphology of the produced carbon $[50,51]$. As mentioned previously, the main reasons why methane conversion continued to increase in "the third step" and why the pore size distributions of the catalysts were affected remain uncertain. Therefore, carbon deposits produced on three types of catalysts (10Fe/MRM, 20Fe/MRM, and 30Fe/MRM) were investigated.

Figure 8 shows the SEM images of $20 \mathrm{Fe} / \mathrm{MRM}$ and the carbon deposits formed on it. In Figure 8(a), a loose porous structure is seen, which was assembled by a large number of tiny particles, shown in Figures 5(b) and 5(c). In combination with the results of Figure 6(b), we concluded that a type of high-iron-dispersion catalysts with a loose porous structure assembled by a large number of uniformly particles had been produced. In Figure 8(b), carbon deposits with different structures and sizes formed by CMD over the catalyst and embedded in the pore structure of the catalysts were observed. Therefore, the pore size distributions of the catalysts during CMD were mainly affected by the carbon deposits.

Figure 9 shows TEM images of carbon deposited on fresh catalysts (10Fe/MRM, 20Fe/MRM, and 30Fe/MRM). These carbons were classified into three types based on their shapes and structures: spherical-like carbons, filamentous carbons with a chain-like structure [14], and carbon nanotubes [17, 19] with a long-filament-like structure. The outer diameters of the spherical-like carbons in the TEM images ranged from 40 to $100 \mathrm{~nm}$. Iron species were observed as layers parcelled by carbons, varying in size (from 10 to $60 \mathrm{~nm}$ ) and morphology with a spherical appearance. TEM images of spherical-like carbons have shown that graphite layers of carbons grow with concentric spheres from the central iron species [14], which can be observed in Figure 9(b). The chain-like carbons are seen in Figures 9(c) and 9(d). The walls of the chain-like carbons were uneven, and the hollows of these filamentous carbons were divided into many cells, some of which were filled with iron species. A large number of multiwalled carbon nanotubes were observed in the TEM images (Figures 9(a)-9(f)), showing that the outer and hollow diameters of the carbon nanotubes ranged from 30 to $80 \mathrm{~nm}$ and from 5 to $60 \mathrm{~nm}$, respectively. The range of the carbon nanotube lengths was widely distributed (from several hundreds of nanometers to several tens of microns). However, these three types of carbon deposits all contained a common characteristic: they all consisted of graphite layers formed in an overlay of layer upon layer.

The active metal was observed at the tip of the carbon nanotubes in Figures 9(a) and 9(c). Metal particles are known to form filamentous carbon with almost the same hollow diameter as elemental carbon by methane decomposition $[51,52]$. Previous studies have shown that filamentous carbon formed on metal catalysts helps keep the metal exposed and active [29], and active metal at the tip of filamentous carbon 


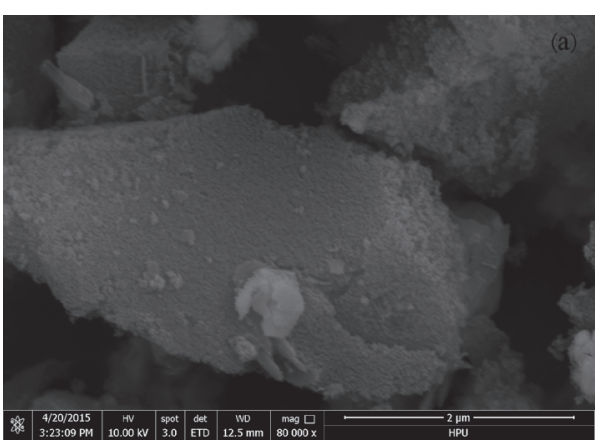

(a)

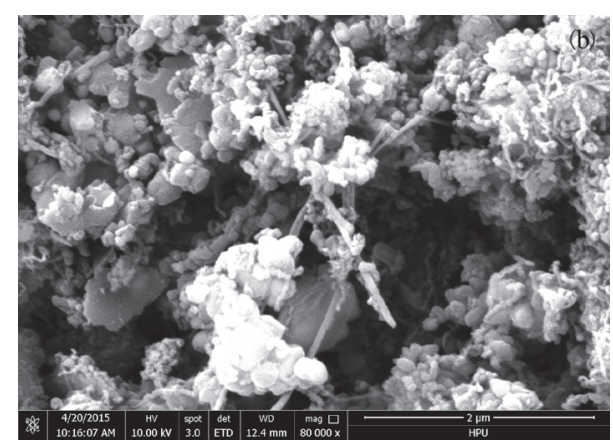

(b)

FIGURE 8: SEM images of 20Fe/MRM catalyst before and after CMD: (a) 20Fe/MRM catalyst; (b) 20Fe/MRM-after CMD.
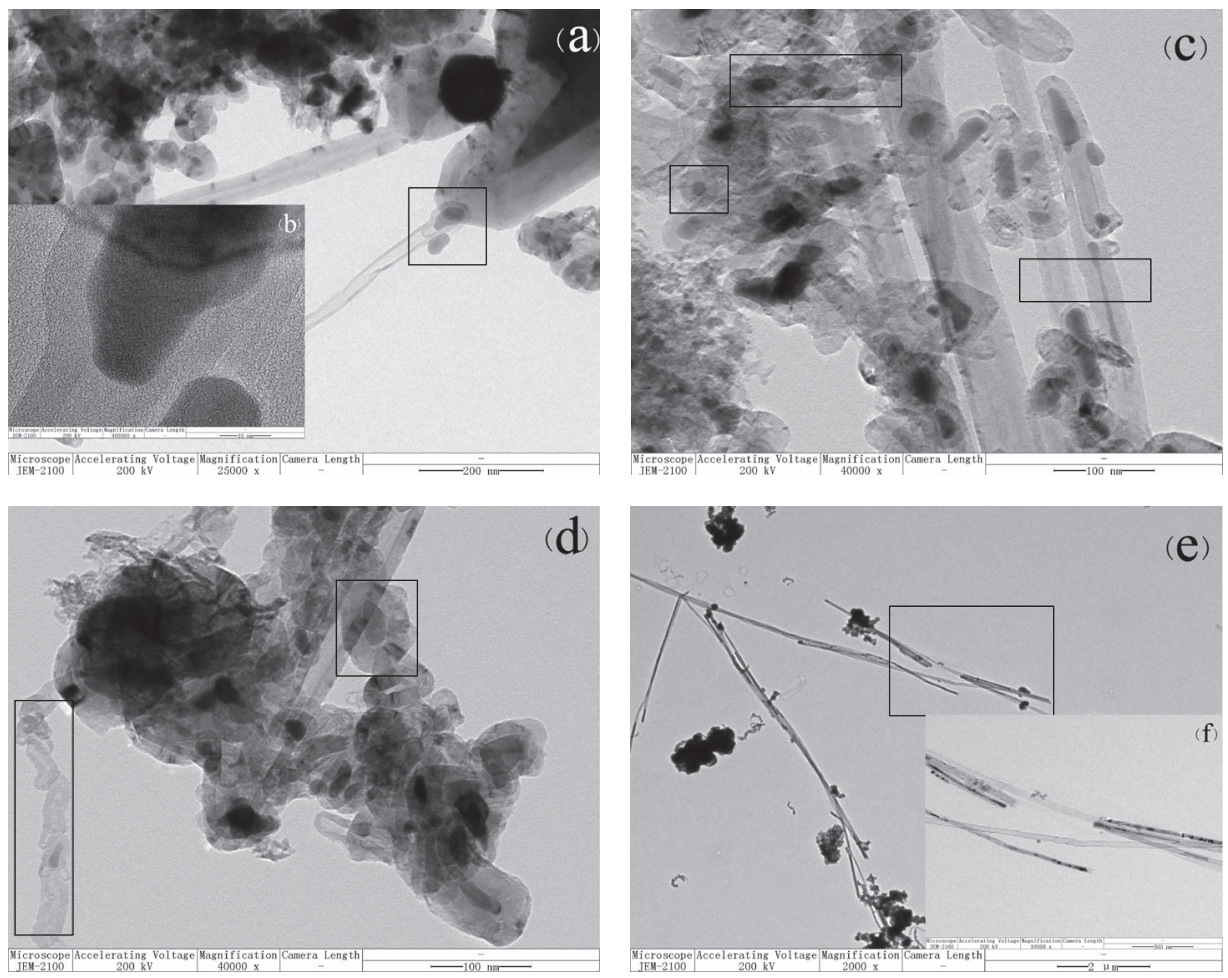

FiguRE 9: TEM images of carbon deposits: the carbons deposited on 10Fe/MRM ((a) and (b)), 20Fe/MRM ((c) and (d)), and 30Fe/MRM ((e) and (f)).

is beneficial for dispersing into carbon deposits. In Figures 9(e) and 9(f), the filamentous carbon with a hollow structure filled in several small metal particles, suggesting that the iron species were gradually divided into smaller ones and covered by graphite layers during methane decomposition [14], causing the iron diffraction peaks $\left(2 \theta\right.$ of $65.006^{\circ}$ and $82.311^{\circ}$ ) in the XRD pattern of $20 \mathrm{Fe} / \mathrm{MRM}$-after CMD to become weaker than those of $20 \mathrm{Fe} / \mathrm{MRM}$ catalyst. The fragmentation of iron species followed by covering with graphite layers should deactivate the catalysts prior to CMD because the iron species cannot make contact with the methane molecules [53]. $\mathrm{Fe}_{3} \mathrm{C}$ forms in areas where iron species were covered with graphite, which was found in the XRD pattern (see Figure 2). Therefore, the activity of the catalyst mainly depends on the remaining active metal that has not been covered by graphite layers during methane decomposition, and formation of filamentous carbon helps keep catalysts active.

Moreover, another factor that caused the catalysts not to deactivate is probably ascribed to continuous production of carbon deposits, even though the methane flow rate was stable. However, continuous production of the carbon deposits caused a steady increase in the weight of the catalyst bed, indirectly leading to a decline in the volumetric hourly space velocity (VHSV).

$$
\operatorname{VHSV}\left(\mathrm{L} / \mathrm{h} \cdot \mathrm{g}_{\text {cat }}\right)=\frac{f_{\text {met }}(\mathrm{L} / \mathrm{h})}{w_{\text {cat }}\left(\mathrm{g}_{\text {cat }}\right)},
$$


where $f_{\text {met }}$ is flow rate of methane and $w_{\text {cat }}$ is weight of the catalyst bed.

In addition, many studies about catalytic methane decomposition over carbon materials have been completed [23], and one study [54] regarding carbon fibres with $\mathrm{Ni}$ support showed that the carbon fibres (prepared by decomposition of $\mathrm{CH}_{4}$ ) and graphitized carbon fibres ( $\mathrm{GrCF}$ ) had better catalytic activity and stability than activated carbon powder or graphite for CMD. Thus, this may prove that the filamentous carbon produced in this study improved methane conversion. Therefore, the methane conversion continued to increase (in the third step) with reaction time because of three factors: the fact that the remaining active metal had not been covered by graphite layers, continuous decline of volumetric hourly space velocity, and accumulation of filamentous carbon.

\section{Conclusions}

A type of modified red mud-supported Fe catalysts was prepared using the homogeneous precipitation method, and the activity of the catalysts for catalytic methane decomposition was determined. The BET and SEM results showed that the $x \mathrm{Fe} / \mathrm{MRM}$ catalysts prepared in this study were all assembled by a large number of uniform nanoscale particles, the surface areas and pore volumes of the catalysts were significantly improved, and the pore sizes were distributed from 3 to $12 \mathrm{~nm}$. Moreover, the active metal Fe and the other elements in the catalysts were uniformly distributed over the catalysts. The $x \mathrm{Fe} / \mathrm{MRM}$ catalysts had better activity than RM and MRM and exhibited similar behaviours (three-step) during CMD. The maintenance of catalyst activity in the final stage of the reaction was attributed to three factors: the fact that the remaining active metal had not been covered by graphite layers, continuous decline of volumetric hourly space velocity, and accumulation of filamentous carbon.

\section{Conflicts of Interest}

The authors declare that there are no conflicts of interest in the contents of this paper.

\section{Acknowledgments}

This work was supported by the "Strategic Priority Research Program Climate Change: Carbon Budget and Related Issues" of the Chinese Academy of Sciences (Grant no. XDA05010300).

\section{References}

[1] K. Trchounian and A. Trchounian, "Hydrogen production from glycerol by Escherichia coli and other bacteria: An overview and perspectives," Applied Energy, vol. 156, pp. 174-184, 2015.

[2] Y.-R. He, F.-F. Yan, H.-Q. Yu, S.-J. Yuan, Z.-H. Tong, and G.-P. Sheng, "Hydrogen production in a light-driven photoelectrochemical cell," Applied Energy, vol. 113, pp. 164-168, 2014.

[3] R. P. B. Ramachandran, G. Van Rossum, W. P. M. Van Swaaij, and S. R. A. Kersten, "Preliminary assessment of synthesis gas production via hybrid steam reforming of methane and glycerol," Energy \& Fuels, vol. 25, no. 12, pp. 5755-5766, 2011.

[4] K. D. Dewoolkar and P. D. Vaidya, "Improved hydrogen production by sorption-enhanced steam methane reforming over hydrotalcite- and calcium-based hybrid materials," Energy \& Fuels, vol. 29, no. 6, pp. 3870-3878, 2015.

[5] A. J. De Abreu, A. F. Lucrédio, and E. M. Assaf, "Ni catalyst on mixed support of $\mathrm{CeO}_{2}-\mathrm{ZrO}_{2}$ and $\mathrm{Al}_{2} \mathrm{O}_{3}$ : effect of composition of $\mathrm{CeO}_{2}-\mathrm{ZrO}_{2}$ solid solution on the methane steam reforming reaction," Fuel Processing Technology, vol. 102, pp. 140-145, 2012.

[6] K.-M. Kang, H.-W. Kim, I.-W. Shim, and H.-Y. Kwak, "Catalytic test of supported Ni catalysts with core/shell structure for dry reforming of methane," Fuel Processing Technology, vol. 92, no. 6, pp. 1236-1243, 2011.

[7] Y. Kathiraser, U. Oemar, E. T. Saw, Z. Li, and S. Kawi, "Kinetic and mechanistic aspects for $\mathrm{CO} 2$ reforming of methane over $\mathrm{Ni}$ based catalysts," Chemical Engineering Journal, vol. 278, pp. 6278, 2015.

[8] M. Toledo, F. González, and J. Ellzey, "Hydrogen production from methanol and ethanol partial oxidation," Energy \& Fuels, vol. 28, no. 5, pp. 3453-3459, 2014.

[9] K. Zhang, L. Liu, J. Sunarso, H. Yu, V. Pareek, and S. Liu, "Highly stable external short-circuit-assisted oxygen ionic transport membrane reactor for carbon dioxide reduction coupled with methane partial oxidation," Energy \& Fuels, vol. 28, no. 1, pp. 349-355, 2014.

[10] M. H. Rafiq, H. A. Jakobsen, and J. E. Hustad, "Modeling and simulation of catalytic partial oxidation of methane to synthesis gas by using a plasma-assisted gliding arc reactor," Fuel Processing Technology, vol. 101, pp. 44-57, 2012.

[11] C. Ding, W. Liu, J. Wang et al., "One step synthesis of mesoporous $\mathrm{NiO}-\mathrm{Al}_{2} \mathrm{O}_{3}$ catalyst for partial oxidation of methane to syngas: The role of calcination temperature," Fuel, vol. 162, pp. 148-154, 2015.

[12] L. B. Avdeeva, T. V. Reshetenko, Z. R. Ismagilov, and V. A. Likholobov, "Iron-containing catalysts of methane decomposition: Accumulation of filamentous carbon," Applied Catalysis A: General, vol. 228, no. 1-2, pp. 53-63, 2002.

[13] A. A. Ibrahim, A. H. Fakeeha, A. S. Al-Fatesh, A. E. Abasaeed, and W. U. Khan, "Methane decomposition over iron catalyst for hydrogen production," International Journal of Hydrogen Energy, vol. 40, no. 24, pp. 7593-7600, 2015.

[14] S. Takenaka, M. Serizawa, and K. Otsuka, "Formation of filamentous carbons over supported Fe catalysts through methane decomposition," Journal of Catalysis, vol. 222, no. 2, pp. 520-531, 2004.

[15] J. L. Pinilla, R. Utrilla, R. K. Karn et al., "High temperature ironbased catalysts for hydrogen and nanostructured carbon production by methane decomposition," International Journal of Hydrogen Energy, vol. 36, no. 13, pp. 7832-7843, 2011.

[16] A. E. Awadallah, A. A. Aboul-Enein, and A. K. Aboul-Gheit, "Impact of group VI metals addition to $\mathrm{Co} / \mathrm{MgO}$ catalyst for non-oxidative decomposition of methane into $\mathrm{COx}$-free hydrogen and carbon nanotubes," Fuel, vol. 129, pp. 27-36, 2014.

[17] D. Torres, J. L. Pinilla, M. J. Lázaro, R. Moliner, and I. Suelves, "Hydrogen and multiwall carbon nanotubes production by catalytic decomposition of methane: Thermogravimetric analysis and scaling-up of Fe-Mo catalysts," International Journal of Hydrogen Energy, vol. 39, no. 8, pp. 3698-3709, 2014.

[18] A. E. Awadallah, M. S. Mostafa, A. A. Aboul-Enein, and S. A. Hanafi, "Hydrogen production via methane decomposition 
over Al2O 3-TiO2 binary oxides supported Ni catalysts: Effect of Ti content on the catalytic efficiency," Fuel, vol. 129, pp. 68-77, 2014.

[19] W. Wang, H. Wang, Y. Yang, and S. Jiang, "Ni-SiO 2 and Ni$\mathrm{Fe}-\mathrm{SiO}_{2}$ catalysts for methane decomposition to prepare hydrogen and carbon filaments," International Journal of Hydrogen Energy, vol. 37, no. 11, pp. 9058-9066, 2012.

[20] M. Pudukudy and Z. Yaakob, "Methane decomposition over Ni, $\mathrm{Co}$ and Fe based monometallic catalysts supported on sol gel derived SiO2 microflakes," Chemical Engineering Journal, vol. 262, pp. 1009-1021, 2015.

[21] H. Y. Wang and A. C. Lua, "Deactivation and kinetic studies of unsupported $\mathrm{Ni}$ and $\mathrm{Ni}-\mathrm{Co}-\mathrm{Cu}$ alloy catalysts used for hydrogen production by methane decomposition," Chemical Engineering Journal, vol. 243, pp. 79-91, 2014.

[22] S. Y. Lee, J. H. Kwak, G. Y. Han, T. J. Lee, and K. J. Yoon, “Characterization of active sites for methane decomposition on carbon black through acetylene chemisorption," Carbon, vol. 46, no. 2, pp. 342-348, 2008.

[23] J. Zhang, L. Jin, X. He, S. Liu, and H. Hu, "Catalytic methane decomposition over activated carbons prepared from direct coal liquefaction residue by $\mathrm{KOH}$ activation with addition of $\mathrm{SiO}_{2}$ or SBA-15," International Journal of Hydrogen Energy, vol. 36, no. 15, pp. 8978-8984, 2011.

[24] N. Muradov, F. Smith, and A. T-Raissi, "Catalytic activity of carbons for methane decomposition reaction," Catalysis Today, vol. 102-103, pp. 225-233, 2005.

[25] H. F. Abbas and W. M. A. Wan Daud, "Thermocatalytic decomposition of methane using palm shell based activated carbon: Kinetic and deactivation studies," Fuel Processing Technology, vol. 90, no. 9, pp. 1167-1174, 2009.

[26] J. Zhang, L. Jin, H. Hu, and Y. Xun, "Effect of composition in coal liquefaction residue on catalytic activity of the resultant carbon for methane decomposition," Fuel, vol. 96, pp. 462-468, 2012.

[27] I. Suelves, J. L. Pinilla, M. J. Lázaro, and R. Moliner, "Carbonaceous materials as catalysts for decomposition of methane," Chemical Engineering Journal, vol. 140, no. 1-3, pp. 432-438, 2008.

[28] L. Jin, H. Si, J. Zhang et al., "Preparation of activated carbon supported $\mathrm{Fe}-\mathrm{Al}_{2} \mathrm{O}_{3}$ catalyst and its application for hydrogen production by catalytic methane decomposition," International Journal of Hydrogen Energy, vol. 38, no. 25, pp. 10373-10380, 2013.

[29] J. Zhang, L. Jin, Y. Li, and H. Hu, "Ni doped carbons for hydrogen production by catalytic methane decomposition," International Journal of Hydrogen Energy, vol. 38, no. 10, pp. 3937-3947, 2013.

[30] M. Szymańska, A. Malaika, P. Rechnia, A. Miklaszewska, and M. Kozłowski, "Metal/activated carbon systems as catalysts of methane decomposition reaction," Catalysis Today, vol. 249, pp. 94-102, 2015.

[31] X. Li, G. Zhu, S. Qi, J. Huang, and B. Yang, "Simultaneous production of hythane and carbon nanotubes via catalytic decomposition of methane with catalysts dispersed on porous supports," Applied Energy, vol. 130, pp. 846-852, 2014.

[32] A. V. Krestinin, A. V. Raevskii, and M. B. Kislov, "Growth rate of carbon filaments during methane pyrolysis on an iron catalyst with analysis using a kinetic-thermodynamic approach," Carbon, vol. 46, no. 11, pp. 1450-1463, 2008.

[33] J. L. Pinilla, R. Utrilla, M. J. Lázaro, R. Moliner, I. Suelves, and A. B. García, "Ni- and Fe-based catalysts for hydrogen and carbon nanofilament production by catalytic decomposition of methane in a rotary bed reactor," Fuel Processing Technology, vol. 92, no. 8, pp. 1480-1488, 2011.

[34] J. Alvarez, R. Rosal, H. Sastre, and F. V. Díez, "Characterization and deactivation studies of an activated sulfided red mud used as hydrogenation catalyst," Applied Catalysis A: General, vol. 167, no. 2, pp. 215-223, 1998.

[35] J. Halász, M. Hodos, I. Hannus, G. Tasi, and I. Kiricsi, "Catalytic detoxification of C2-chlorohydrocarbons over iron-containing oxide and zeolite catalysts," Colloids and Surfaces A: Physicochemical and Engineering Aspects, vol. 265, no. 1-3, pp. 171-177, 2005.

[36] S. Sushil and V. S. Batra, "Modification of red mud by acid treatment and its application for CO removal," Journal of Hazardous Materials, vol. 203-204, pp. 264-273, 2012.

[37] F. N. Pei, L. Li, S. Wang, Z. Zhu, G. Lu, and Z. Yan, "Catalytic ammonia decomposition over industrial-waste-supported $\mathrm{Ru}$ catalysts," Environmental Science \& Technology, vol. 41, no. 10, pp. 3758-3762, 2007.

[38] J. R. Paredes, S. Ordóñez, A. Vega, and F. V. Díez, "Catalytic combustion of methane over red mud-based catalysts," Applied Catalysis B: Environmental, vol. 47, no. 1, pp. 37-45, 2004.

[39] M. Balakrishnan, V. S. Batra, J. S. J. Hargreaves et al., "Hydrogen production from methane in the presence of red mud-making mud magnetic," Green Chemistry, vol. 11, no. 1, pp. 42-47, 2009.

[40] X. Fang, Q. Liu, P. Li, H. Li, F. Li, and G. Huang, "A Nanomesoporous Catalyst from Modified Red Mud and Its Application for Methane Decomposition to Hydrogen Production," Journal of Nanomaterials, vol. 2016, Article ID 6947636, 2016.

[41] J.-L. Cao, Z.-L. Yan, Q.-F. Deng et al., "Mesoporous modifiedred-mud supported Ni catalysts for ammonia decomposition to hydrogen," International Journal of Hydrogen Energy, vol. 39, no. 11, pp. 5747-5755, 2014.

[42] S. Sushil, A. M. Alabdulrahman, M. Balakrishnan et al., "Carbon deposition and phase transformations in red mud on exposure to methane," Journal of Hazardous Materials, vol. 180, no. 1-3, pp. 409-418, 2010.

[43] A. Alp and M. S. Goral, "The influence of soda additive on the thermal properties of red mud," Journal of Thermal Analysis and Calorimetry, vol. 73, no. 1, pp. 201-207, 2003.

[44] A. Atasoy, "An investigation on characterization and thermal analysis of the Aughinish red mud," Journal of Thermal Analysis and Calorimetry, vol. 81, no. 2, pp. 357-361, 2005.

[45] H. Nath, P. Sahoo, and A. Sahoo, "Characterization of Red Mud treated under high temperature fluidization," Powder Technology, vol. 269, pp. 233-239, 2015.

[46] M. Antunes L P, S. Couperthwaite J, F. Da Conceição T et al., "Red Mud from Brazil: Thermal Behavior and Physical Properties," Industrial \& Engineering Chemistry Research, vol. 51, no. 2, pp. 775-779, 2012.

[47] H. G. El-Shobaky and M. M. Mokhtar, "Effect of $\mathrm{Li}_{2} \mathrm{O}$ and $\mathrm{CoO}$-doping of $\mathrm{CuO} / \mathrm{Fe}_{2} \mathrm{O}_{3}$ system on its surface and catalytic properties," Applied Surface Science, vol. 253, no. 24, pp. 94079413, 2007.

[48] S. Takenaka, H. Ogihara, I. Yamanaka, and K. Otsuka, "Decomposition of methane over supported-Ni catalysts: effects of the supports on the catalytic lifetime," Applied Catalysis A: General, vol. 217, no. 1-2, pp. 101-110, 2001. 
[49] T. V. Reshetenko, L. B. Avdeeva, V. A. Ushakov et al., "Coprecipitated iron-containing catalysts (Fe-Al2O3, Fe-Co-Al2O3, Fe$\mathrm{Ni}-\mathrm{Al} 2 \mathrm{O} 3$ ) for methane decomposition at moderate temperatures: Part II. Evolution of the catalysts in reaction," Applied Catalysis A: General, vol. 270, no. 1-2, pp. 87-99, 2004.

[50] H. F. Abbas and W. M. A. Wan Daud, "Hydrogen production by methane decomposition: A review," International Journal of Hydrogen Energy, vol. 35, no. 3, pp. 1160-1190, 2010.

[51] Y. Li, B. Zhang, X. Xie, J. Liu, Y. Xu, and W. Shen, "Novel Ni catalysts for methane decomposition to hydrogen and carbon nanofibers," Journal of Catalysis, vol. 238, no. 2, pp. 412-424, 2006.

[52] S. Takenaka, E. Kato, Y. Tomikubo, and K. Otsuka, "Structural change of Ni species during the methane decomposition and the subsequent gasification of deposited carbon with $\mathrm{CO} 2$ over supported Ni catalysts," Journal of Catalysis, vol. 219, no. 1, pp. 176-185, 2003.

[53] M. A. Ermakova, D. Y. Ermakov, and G. G. Kuvshinov, "Effective catalysts for direct cracking of methane to produce hydrogen and filamentous carbon. Part I. Nickel catalysts," Applied Catalysis A: General, vol. 201, no. 1, pp. 61-70, 2000.

[54] K. Otsuka, H. Ogihara, and S. Takenaka, "Decomposition of methane over Ni catalysts supported on carbon fibers formed from different hydrocarbons," Carbon, vol. 41, no. 2, pp. 223233, 2003. 

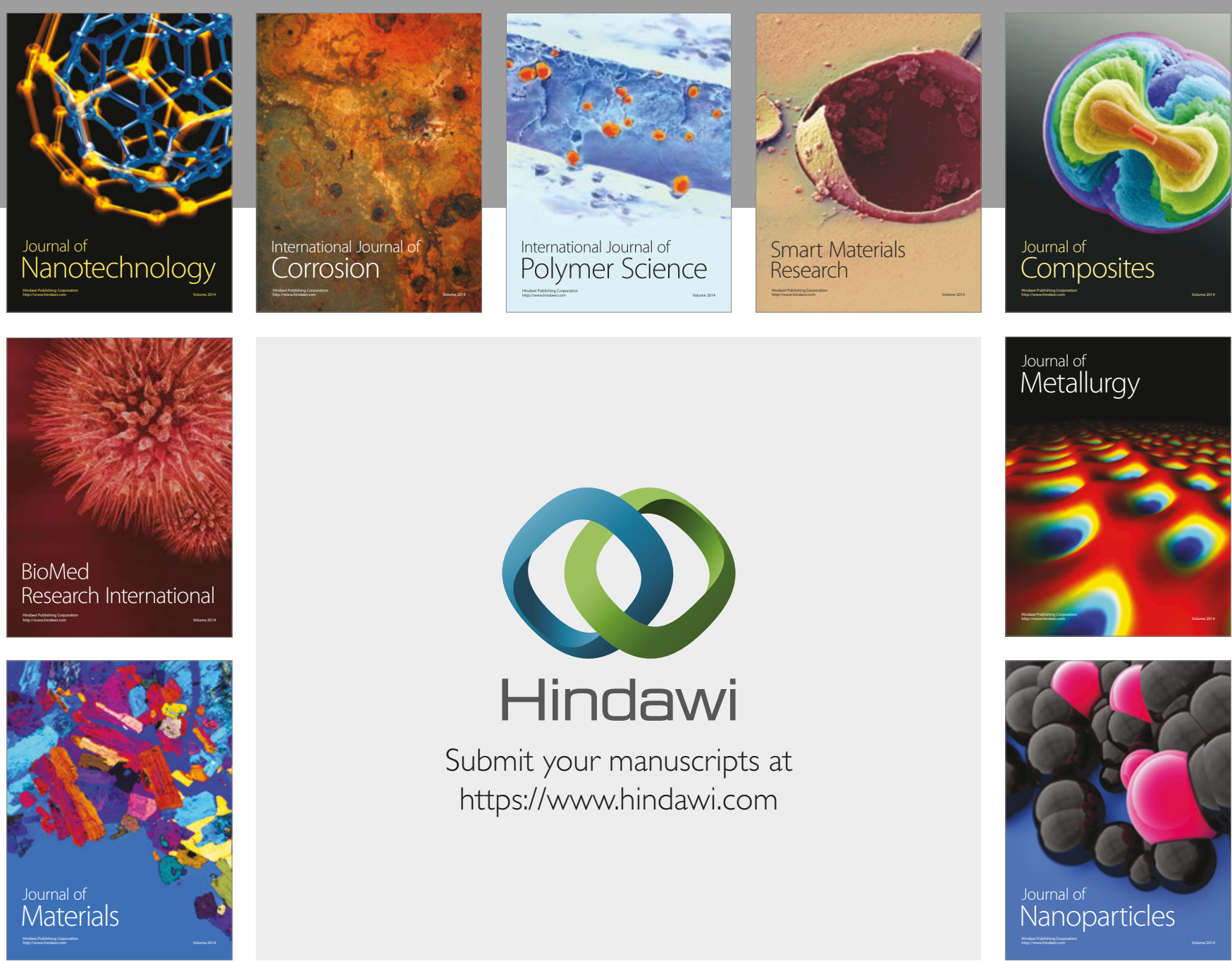

\section{Hindawi}

Submit your manuscripts at

https://www.hindawi.com
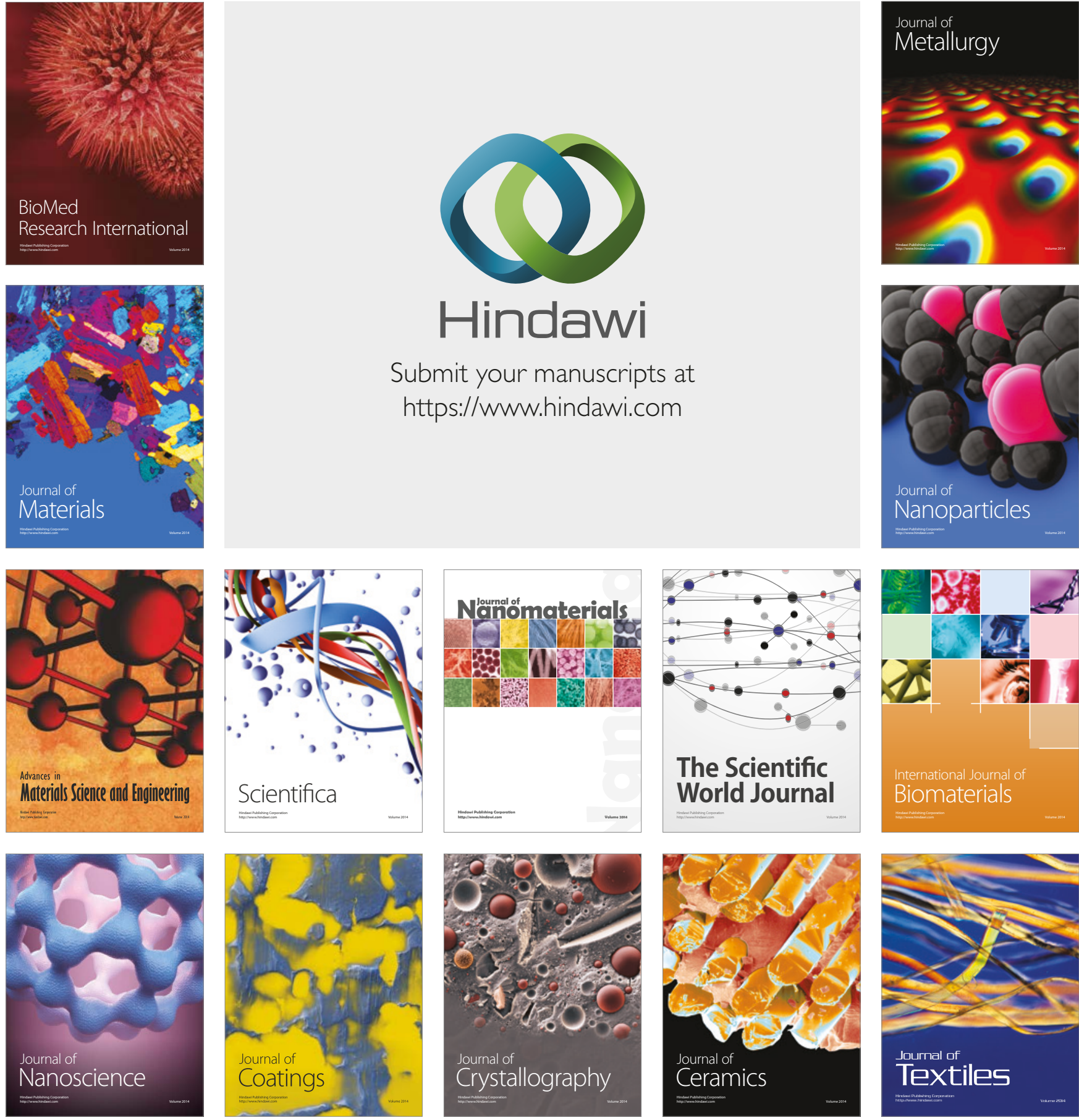

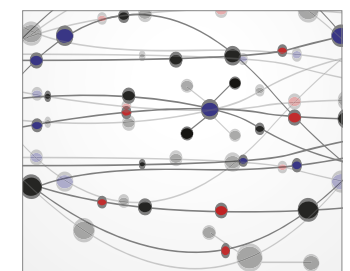

The Scientific World Journal
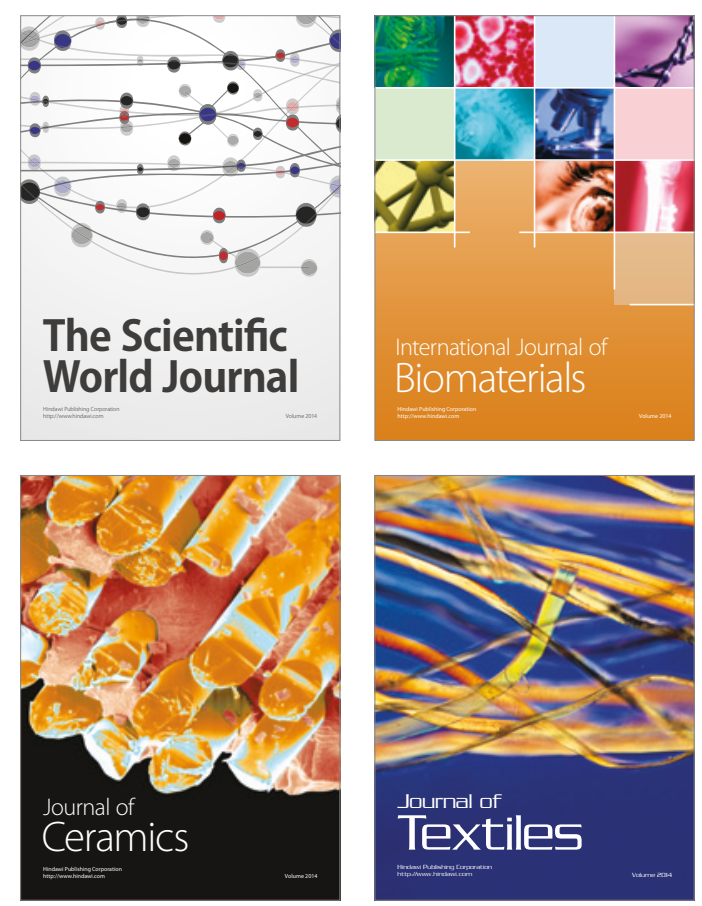